\title{
Prediction of railway induced ground vibration through multibody and finite element modelling
}

\author{
G. Kouroussis and O. Verlinden \\ Université de Mons - UMONS, Faculty of Engineering, Department of Theoretical Mechanics, \\ Dynamics and Vibrations, Place du Parc 20, 7000 Mons, Belgium \\ Correspondence to: G. Kouroussis (georges.kouroussis@umons.ac.be)
}

Received: 23 November 2012 - Revised: 19 February 2013 - Accepted: 5 April 2013 - Published: 16 April 2013

\begin{abstract}
The multibody approach is now recognized as a reliable and mature computer aided engineering tool. Namely, it is commonly used in industry for the design of road or railway vehicles. The paper presents a framework developed for predicting the vibrations induced by railway transportation. Firstly, the vehicle/track subsystem is simulated, on the basis of the home-made $\mathrm{C}++$ library EasyDyn, by mixing the multibody model of the vehicle and the finite element model of the track, coupled to each other through the wheel/rail contact forces. Only the motion in the vertical plane is considered, assuming a total symmetry between left and right rails. This first step produces the time history of the forces exerted by the ballast on the foundation, which are then applied to a full 3-D FEM model of the soil, defined under the commercial software ABAQUS. The paper points out the contribution of the pitch motion of the bogies and carbodies which were neglected in previous publications, as well as the interest of the so-called coupled-lumped mass model (CLM) to represent the influence of the foundation in the track model. The potentialities of the model are illustrated on the example of the Thalys high-speed train, riding at $300 \mathrm{~km} \mathrm{~h}^{-1}$ on the Belgian site of Mévergnies.
\end{abstract}

\section{Introduction}

After more than $40 \mathrm{yr}$ of research and development, multibody dynamics simulation has now reached scientific and commercial maturity: several books exist describing well established methods to build and integrate the equations of motion (Géradin and Cardona, 2000; Garcia de Jalon and Bayo, 1993; Shabana, 2005; Bauchau, 2011), and commercial software's like MSC/ADAMS, SIMPACK or LMS/Virtual.Lab Motion are commonly used in robotics, car or railway industry along with other computer-aided engineering tools like finite element. The coupling of multibody systems with other disciplines offers nowadays a rich area of new developments. For example mechatronic systems which need to integrate specific equations related to controllers, actuators or sensors, or biomechanics where behaviour equations of tissues like muscles must be mixed with the ones of the mechanical system constituted by the skeleton and the limbs. In this paper, we will present a similar application: the multibody model of a vehicle and the finite element model of the track are merged in order to constitute a framework aiming at predicting the vibrations induced by railway vehicles. The model is used as a first step: it provides the time history of the forces exerted on the foundation, which are in turn used as inputs in a 3-D finite element of the soil. The complete process is performed in the time domain.

The focus of this study is to describe the approach, with a particular attention on the vehicle/track subsystem which involves the multibody model of the vehicle. The paper will first present a brief summary of the state of the art in terms of railway induced ground vibrations. The general organization of the global simulation framework will then be explained. The fourth section will detail the vehicle/track model with a focus on recent improvements either on the vehicle and track models. The potentialities of the approach will then be illustrated through the example of the Thalys high-speed train (HST). The paper is ended with some conclusions. 


\section{Railway-induced ground vibrations}

It is largely admitted that railway transport constitutes a proper solution to traffic congestion and pollution observed in big cities. However, it also brings nuisances that must remain limited to avoid opposition of the dwellers. Noise and vibrations generated by the vehicle riding on the localized or distributed irregularities of the track are one of the usual reasons of complaint. It is then important to develop technical solutions to mitigate the railway vibrations, ideally from the beginning of the track and vehicle design. This requires reliable simulation tools, able to reproduce with a sufficient accuracy the propagation of vibrations, from the wheel-rail interface to the buildings, through the track and a medium, the soil, fundamentally inhomogeneous and infinite in three directions.

The problem of railway induced vibrations clearly involves 3 components: the vehicle, the track (rails, sleepers and ballast) and the soil.

Initially, the vehicle has often been reduced to a simple moving loaded mass (Wang and Zeng, 2004) or eventually a succession of the latter (Lefeuve-Mesgouez et al., 2002). With such a simplification, the origin of vibration lies in the irregular deflection of the track which induces up and down motion of the moving mass: the rail indeed offers a larger rigidity (and then a smaller displacement) above the sleepers than between the latter. This effect is sufficient to explain the so-called soil critical speed: when the speed of a train gets above the Rayleigh wave velocity of the superficial layer, it has a tendency to induce large vibrations. This phenomenon is generally observed for soft soils. Many works, as those proposed by Kaynia et al. (2000), Takemiya and Bian (2005) or Kouroussis et al. (2012c), have been conducted to reproduce by simulation this phenomenon. However, other sources contribute to the vibration content, among which the track and wheel irregularities and the vehicle dynamics. To reproduce this contribution, a more detailed model of the vehicle becomes necessary (Kouroussis et al., 2010). For example, Costa et al. $(2011,2012)$ have recently identified the influence and relevance of the mechanical properties of the train and have confirmed that the unsprung and semisprung masses must be included in the prediction model. In parallel, Kouroussis et al. (2012b) have analysed the vibratory effect of the unsprung masses in the specific case of the tramway of Brussels, showing that a modification of the resilient wheel stiffness notably reduces the ground vibrations when the vehicle is coming up against local rail defects.

The track is usually considered through a finite element model (Knothe and Grassie, 1993; Zhai and Sun, 1994). The rail is built from beam elements while lumped masses represent the sleepers, connected by springs and dampers to the rail and to the ground. One more layer of lumped masses can possibly be added to take into account the effect of the foundation in the track model.
Two principal approaches are used to simulate the wave propagation through the soil: the finite element method (FEM) and the boundary element method (BEM). Initially, BEM was preferably used due its natural ability to represent infinite domains and its good computational efficiency when the problem is formulated in the frequency domain (Do Rêgo Silva, 1994). However, the method becomes cumbersome when dealing with complex geometries, while frequency domain is limited to linear problems. In parallel, the continuously increasing power of computers and the development of infinite elements have opened the door to FEM models and it is presently possible to manage fully three-dimensional soil models, either in frequency (Wang et al., 2008) and, more recently in time domain (Kouroussis et al., 2011e). Indeed, Kouroussis et al. (2011d, 2009) have demonstrated that it is possible, in time domain, to alleviate the requirements in terms of domain and element size simulation. Let us also mention that some authors have developed combined BEM/FEM models (Galvín and Domínguez, 2009; François et al., 2009).

\section{Railway vibration prediction model}

A complete description of the model that we developed for predicting the vibrations induced by railway traffic can be found in Kouroussis et al. (2012a). Its main characteristics are the following:

- The simulation is performed in the time domain and in two successive steps (Fig. 1): firstly the simulation of the vehicle/track subsystem, whose result is the time history of the forces exerted by the track on the soil and, secondly, the simulation of the response of the soil to these forces through a finite element model.

- The vehicle/track subsystem is processed under the home-made framework EasyDyn and merges the nonlinear equations of motion of the vehicle defined as a multibody model and the linear equations of a finite element model of the track. So far, a perfect symmetry has been assumed between left and right sides so that the motion is restricted to the vertical plane.

- The response of the ground is simulated under the commercial software ABAQUS. A particular care is given to the definition of the boundary conditions in order to get the best representation of the domain infinity and in particular to avoid wave reflection.

Although the track is modelled with finite elements, it is associated with the vehicle multibody model of the track instead of the finite element model of soil. The reasons are a good description of the contact location without additional artefacts (as for example wheel elements, Ju, 2009) and, for some cases (presence of a singular rail surface defect), the vehicle/track interaction (Kouroussis et al., 2010). Complete 


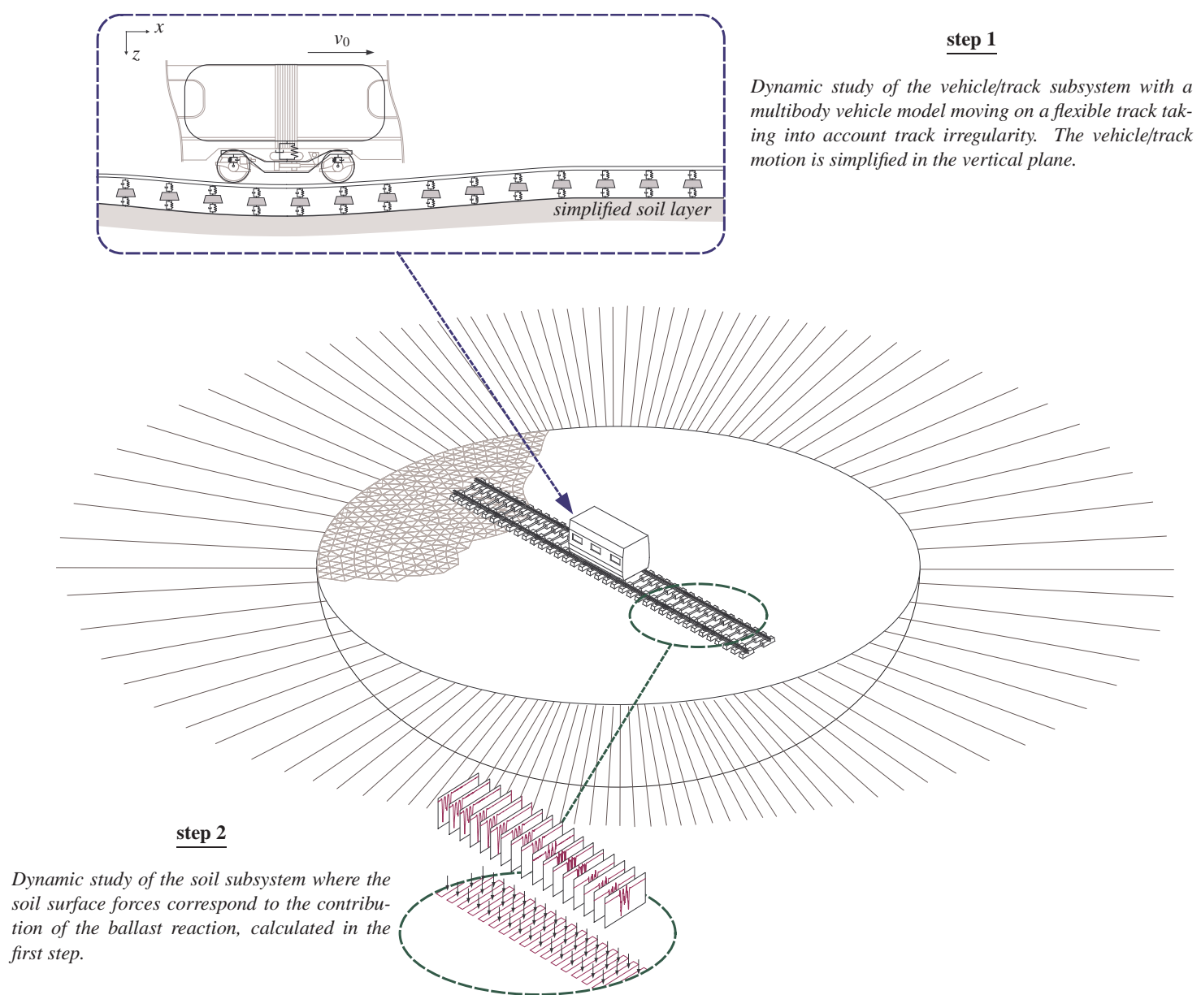

Figure 1. Vehicle/track/soil model, working in two successive steps.

models exist therefore combining multibody and finite element approaches in a single application for vehicle/track/soil analysis (see for example, Connolly et al., 2013).

The prediction model has been used in various practical cases and was successfully confronted to experimental results (Kouroussis et al., 2010, 2011e, 2012b,c, 2013). The main hypothesis in the approach relies in the two step strategy which assumes some decoupling between the track and the soil. However, it turns out that the hypothesis is reasonable as far as the mechanical impedance of the rail, as seen from the vehicle, is well represented, including the possible dynamic coupling between the sleepers through the soil. With classical track models where the soil is considered only through the stiffness under the sleepers (generally known as Winkler foundation, this term being used for continuously supported track and for discrete model as well as), the hypothesis is valid if the soil is sufficiently stiff, which is the case in most of railway lines (Kouroussis et al., 2011e, 2012a). With softer soils, the authors have proposed an enhanced track model, referred to as the coupled lumped mass model (CLM), which offers a faithful representation of soft soils impedance in the requested frequency range (Kouroussis et al., 2011b). In this paper, we will focus on the vehicle/track model.

\section{Vehicle/track model}

\subsection{Global structure}

The developed model merges the equations of motion of the vehicle, which have the form usually encountered in multibody system dynamics

$\mathbf{M}_{\mathrm{v}}\left(\boldsymbol{q}_{\mathrm{v}}\right) \cdot \ddot{\boldsymbol{q}}_{\mathrm{v}}+\boldsymbol{h}_{\mathrm{v}}\left(\boldsymbol{q}_{\mathrm{v}}, \dot{\boldsymbol{q}}_{\mathrm{v}}, t\right)=\boldsymbol{f}_{\mathrm{v}}\left(\boldsymbol{q}_{\mathrm{v}}, \boldsymbol{q}_{\mathrm{t}}, t\right)$

and the equations of the track, represented by a linear finite element model

$\mathbf{M}_{\mathrm{t}} \cdot \ddot{\boldsymbol{q}}_{\mathrm{t}}+\mathbf{C}_{\mathrm{t}} \cdot \dot{\boldsymbol{q}}_{\mathrm{t}}+\mathbf{K}_{\mathrm{t}} \cdot \boldsymbol{q}_{\mathrm{t}}=\boldsymbol{f}_{\mathrm{t}}\left(\boldsymbol{q}_{\mathrm{v}}, \boldsymbol{q}_{\mathrm{t}}, t\right)$

with

- $\boldsymbol{q}_{\mathrm{v}}$ and $\boldsymbol{q}_{\mathrm{t}}$ the vectors gathering the configuration parameters of the vehicle and track, respectively; 


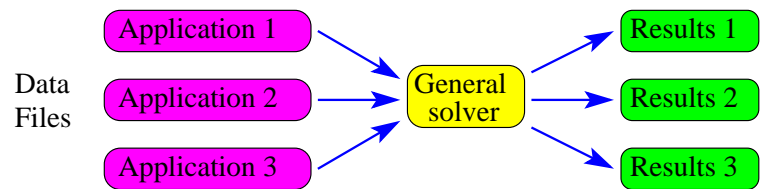

Figure 2. Computational organization with classical coordinates.

- $\mathbf{M}_{\mathrm{v}}$ and $\mathbf{M}_{\mathrm{t}}$ the mass matrices of the vehicle and track, respectively;

- $\boldsymbol{h}_{\mathrm{v}}$ the term gathering the Coriolis, centrifugal and gyroscopic terms of the vehicle;

- $\mathbf{C}_{\mathrm{t}}$ and $\mathbf{K}_{\mathrm{t}}$ the damping and stiffness matrices of the track;

- $f_{\mathrm{t}}$ and $f_{\mathrm{v}}$ representing the external forces (gravity, suspensions, wheel/rail contact forces) exerted on the vehicle and the track respectively.

It appears that the coupling between the vehicle and the track is realized through external forces, and more precisely the contact forces. The latter are determined by considering an elastic contact between the wheel and the rail and then depend on both vehicle and track displacements.

\subsection{Equations of motion of the vehicle}

\subsubsection{The choice of minimal coordinates}

The construction of the equations of motion of the vehicle is based on the so-called minimal coordinates approach, developed by Anantharam and Hiller (1991); Hiller (1993) in the early 90's. With this approach, the configuration parameters used to express the kinematics of the multibody system are arbitrarily chosen but must be independent so that their number is equal to the number of degrees of freedom of the system. Compared to approaches like Cartesian or relative coordinates widely used in commercial products, the minimal coordinates approach has the major drawback to be less systematic as it requires to set up a specific kinematics of the considered system. However, it has the advantage to yield a system of pure ordinary differential equations, without constraint equations, which can be processed in a stable and robust way with standard numerical integration techniques. The approach proves anyway easy to use and efficient with open loop systems like the train model developed in this study.

It is worth to mention that the computational implementation with minimal coordinates is dramatically different from the one classically found with other coordinates. As illustrated in Fig. 2, a multibody simulation software classically consists of a main general solver able to simulate various mechanical systems, each of them being described in a specific data file. With minimal coordinates (Fig. 3), each application actually leads to a dedicated program, which is constructed

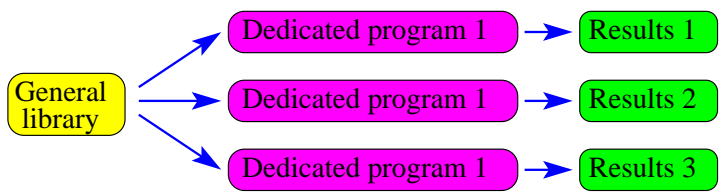

Figure 3. Computational organization with minimal coordinates.

with the help of a multibody library. The latter is expected to provide routines which facilitate the expression of kinematics and forces, and the construction and integration of the equations of motion.

When working with minimal coordinates, the equations of motion generally derive from the application of the d'Alembert's principle. If the system comprises $n_{B}$ bodies and $n_{c p}$ degrees of freedom, the $n_{c p}$ differential equations governing the dynamic behaviour of the mechanical system are built according to

$\sum_{i=1}^{n_{B}}\left[\boldsymbol{d}^{i, j} \cdot\left(\boldsymbol{R}_{i}-m_{i} \boldsymbol{a}_{i}\right)+\boldsymbol{\theta}^{i, j} \cdot\left(\boldsymbol{M}_{G i}-\boldsymbol{\Phi}_{G_{i}} \dot{\boldsymbol{\omega}}_{i}-\boldsymbol{\omega}_{i} \times \boldsymbol{\Phi}_{G_{i}} \boldsymbol{\omega}_{i}\right)\right]=0$

with

- $m_{i}$ and $\boldsymbol{\Phi}_{G_{i}}$ the mass and the central inertia tensor of body $i$;

- $\boldsymbol{R}_{i}$ and $\boldsymbol{M}_{G_{i}}$ the resultant force and moment, at the centre of gravity $G_{i}$, of all applied forces exerted on body $i$;

- $\boldsymbol{a}_{i}$ the acceleration of the centre of gravity of body $i$;

- $\boldsymbol{d}^{i, j}$ and $\boldsymbol{\theta}^{i, j}$ the partial contributions of $\dot{q}_{j}$ in the velocity of the centre of gravity $\boldsymbol{v}_{i}$ and the rotational velocity $\omega_{i}$ of body $i$, respectively, defined by

$$
\begin{array}{cccc}
\boldsymbol{v}_{i} & =\sum_{j=1}^{n_{c p}} \boldsymbol{d}^{i, j} \cdot \dot{q}_{j} \quad \leftrightarrow \quad \boldsymbol{d}^{i, j}=\frac{\partial \boldsymbol{v}_{i}}{\partial \dot{q}_{j}} \\
\boldsymbol{\omega}_{i}= & \sum_{j=1}^{n_{c p}} \boldsymbol{\theta}^{i, j} \cdot \dot{q}_{j} \quad \leftrightarrow & \boldsymbol{\theta}^{i, j}=\frac{\partial \boldsymbol{\omega}_{i}}{\partial \dot{q}_{j}} .
\end{array}
$$

The resulting equations of motion have the classical following form

$\mathbf{M}(\boldsymbol{q}) \cdot \ddot{\boldsymbol{q}}+\boldsymbol{h}(\boldsymbol{q}, \dot{\boldsymbol{q}})=\boldsymbol{g}(\boldsymbol{q}, \dot{\boldsymbol{q}}, t)$

where, for example the mass matrix of dimension $n_{c p} \times n_{c p}$, is obtained by

$\mathbf{M}_{j k}=\sum_{i=1}^{n_{B}}\left[m_{i} \boldsymbol{d}^{i, j} \cdot \boldsymbol{d}^{i, k}+\boldsymbol{\theta}^{i, j} \cdot\left(\boldsymbol{\Phi}_{G_{i}} \cdot \boldsymbol{\theta}^{i, k}\right)\right]$

while $\boldsymbol{h}$ represents the contribution of Coriolis, centrifugal and gyroscpic terms, and $\boldsymbol{f}$ the applied forces.

It turns out that the equations of motion can be constructed if the user provides 


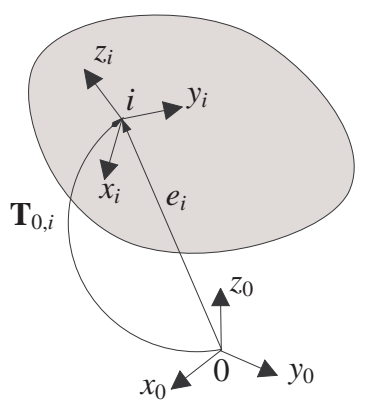

Figure 4. Formalism of homogeneous transformation matrix.

- the kinematics of the system, that's to say the expression of position, velocity, acceleration and partial velocities of each body $i$ of the system in terms of the configuration parameters $\boldsymbol{q}$ and their first and second time derivatives;

- the applied efforts acting on each body $i$.

\subsubsection{Kinematics}

The expression of the complete kinematics, especially at acceleration level and for 3-D systems, is tricky, tedious and source of mistakes. To circumvent this difficulty, the EasyDyn framework provides a symbolic script which automatically generates the expressions of velocities and accelerations from only the position information.

To express the kinematics at position level, the formalism of homogeneous transformation matrices was retained. The position and orientation of each body $i$ is expressed by means of the homogeneous transformation matrix $\mathbf{T}_{0, i}$ giving the situation of the local frame associated with body $i$ with respect to the global reference frame 0 (Fig. 4 ). It is a $4 \times 4$ matrix of the following well-know form

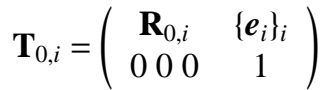

where $\boldsymbol{e}_{i}$ is the coordinate vector of frame $i$ with respect to the global coordinate system 0 , and $\mathbf{R}_{0, i}$ is the rotation tensor describing the orientation of frame $i$ with respect to frame 0 .

Practically, the homogeneous transformation matrices have the deciding advantage to enjoy the following property

$\mathbf{T}_{i, k}=\mathbf{T}_{i, j} \cdot \mathbf{T}_{j, k} \quad \forall i, j, k$.

This means that a complex motion can be elegantly defined as a succession of elementary motions (Fig. 5) like for example

$\mathbf{T}_{0,1}=\mathbf{T}^{\text {rot. } z}(\theta) \cdot \mathbf{T}^{\text {disp }}(0, l, 0)$

expressing a rotation about $z$ of an angle $\theta$ followed by a displacement along the y-axis equal to $l$.

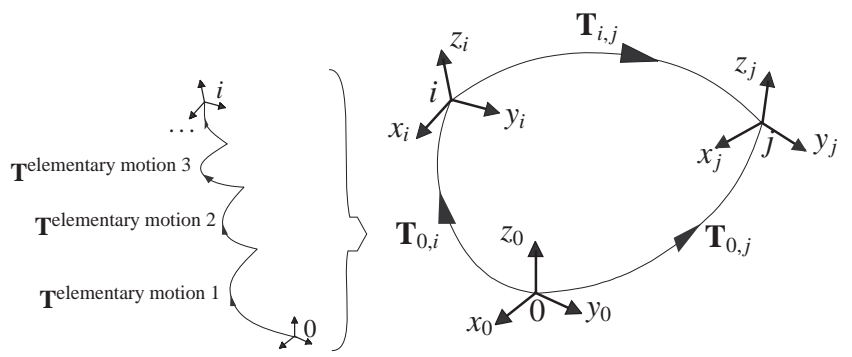

Figure 5. Homogeneous transformation matrices: illustration of the motion decomposition.

Translational and rotational velocities of each body $i$ can then be easily obtained by differentiation of the homogeneous transformation matrix giving its situation

$\left\{\boldsymbol{v}_{i}\right\}_{0}=\frac{\mathrm{d}}{\mathrm{d} t}\left\{\boldsymbol{e}_{i}\right\}_{0}$

$\left\{\tilde{\omega}_{i}\right\}_{0}=\dot{\mathbf{R}}_{0, i} \cdot \mathbf{R}_{0, i}^{T}=\left(\begin{array}{ccc}0 & -\omega_{z} & \omega_{y} \\ \omega_{z} & 0 & -\omega_{x} \\ -\omega_{y} & \omega_{x} & 0\end{array}\right)$

from which accelerations and partial velocities can be determined by one more differentiation.

Under EasyDyn, a symbolic script called CAGeM, which stands for Computer-Aided generation of Motion, takes after the differentiation. The script can be run under MuPAD (SciFace Software GmbH \& Co, 2012) or Xcas/Giac (Parisse and Graeve, 2010), the latter offering a completely open source environment.

\subsubsection{Application to the vehicle modelling}

In the present study, the vehicle is modelled by rigid bodies representing each inertial part of the train: car bodies, bogies, wheelsets and possibly wheel treads in case of compliant wheels (Kouroussis et al., 2012b), interconnected by the primary and secondary suspensions represented by springs and dampers.

To illustrate the use of homogeneous transformation matrices, let us consider the carriage of Fig. 6. The motion of the car body $R_{1}$ and bogies $R_{2}$ and $R_{3}$ is described by their vertical displacements and their pitch angle, involving a total of 6 degrees of freedom $q_{0}$ to $q_{5}$. The resulting homogeneous transformation matrix of the first bogie $R_{2}$ is then written

$$
\begin{aligned}
\mathbf{T}_{0, R_{2}}= & \mathbf{T}^{\text {disp }}\left(v_{0} \cdot t, 0, q_{0}\right) \cdot \mathbf{T}^{\text {rot. } y}\left(q_{1}\right) \cdot \mathbf{T}^{\text {disp }}\left(l_{\mathrm{b}} / 2,0,0\right) \\
& \cdot \mathbf{T}^{\text {rot. } y}\left(-q_{1}\right) \cdot \mathbf{T}^{\text {disp }}\left(0,0, q_{2}\right) \cdot \mathbf{T}^{\text {rot. } y}\left(q_{3}\right)
\end{aligned}
$$

where $\mathbf{T}^{\text {disp }}\left(d_{x}, d_{y}, d_{z}\right)$ represents a translation and $\mathbf{T}^{\text {rot. } y}(\theta)$ a rotation about the y-axis. 

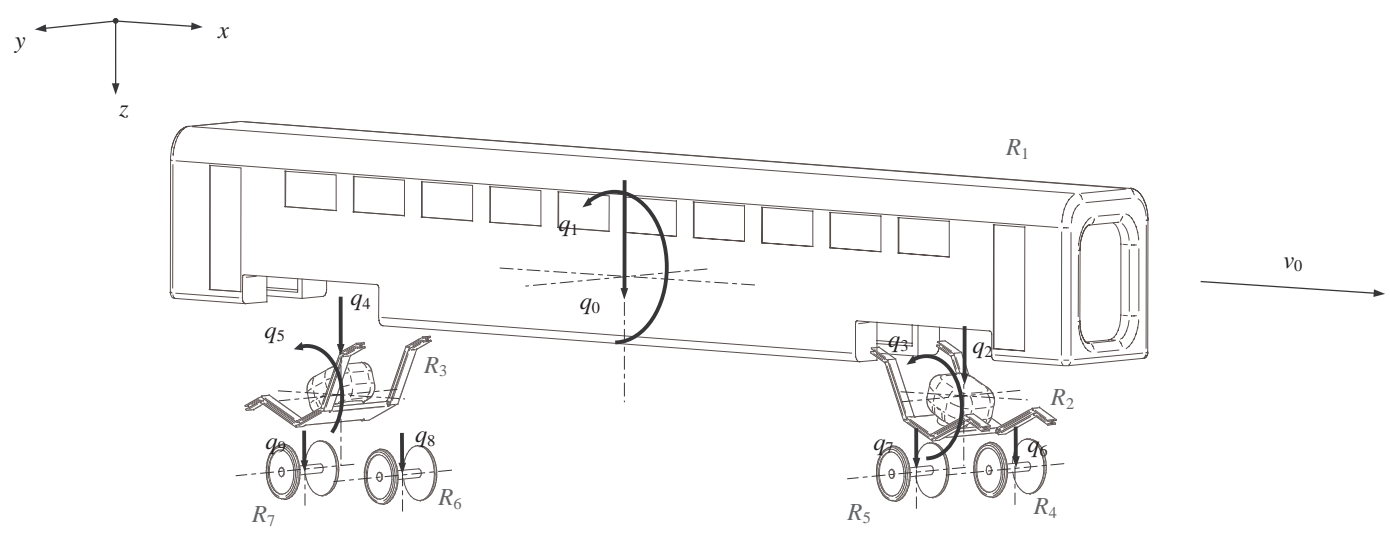

Figure 6. Vehicle modelling - kinematics in the $x z$-plane.

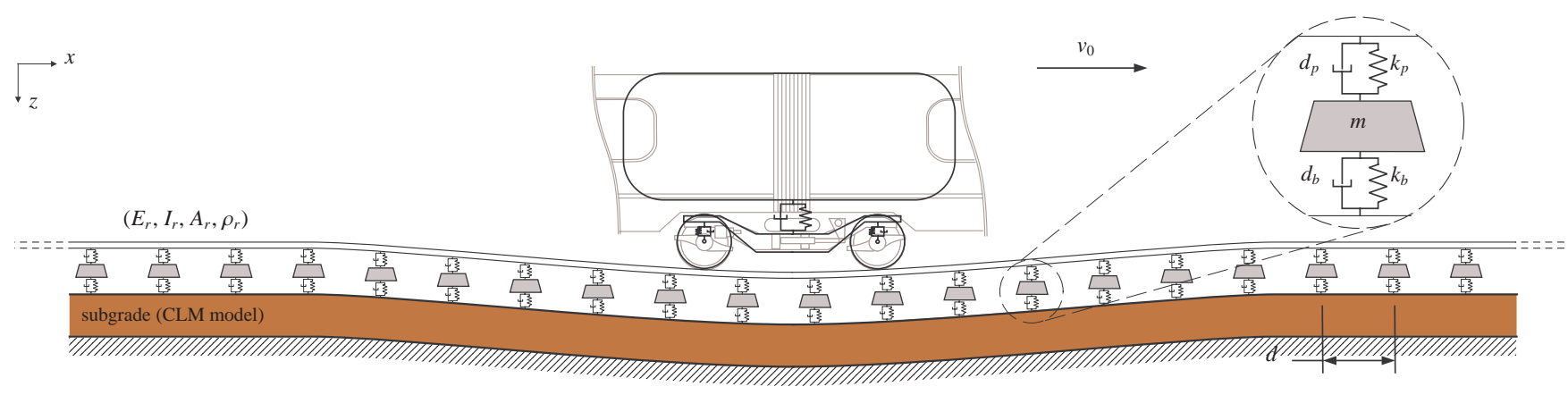

Figure 7. The vehicle/track/foundation model.

The following observations can be made

- the global progression of the vehicle is assured by the $x$ coordinate of the form $v_{0} \cdot t$ with $v_{0}$ the velocity and $t$ the time;

- in this example, $q_{3}$ is desired to strictly correspond to the vertical relative displacement; that is why a backward rotation $-q_{1}$ is imposed between the car and the bogie to compensate the pitch angle $q_{1}$ of the carbody.

On the other hand, the motion of wheelsets $R_{4}$ to $R_{7}$ comes down to only the bounce motion, with respect to the bogie. For instance, the transformation matrix giving the situation of wheelset $R_{7}$ reads

$\mathbf{T}_{0, R_{7}}=\mathbf{T}_{0, R_{2}} \cdot \mathbf{T}^{\text {disp }}\left(-l_{\mathrm{w}} / 2,0,0\right) \cdot \mathbf{T}^{\text {rot. } y}\left(-q_{3}\right) \cdot \mathbf{T}^{\text {disp }}\left(0,0, q_{7}\right)$

where $l_{\mathrm{b}}$ and $l_{\mathrm{w}}$ represent the distances between bogies and wheelsets, respectively.

The formulation is not restrictive, and can be applied without any difficulty to more complex models and/or to threedimensional kinematics.

\subsubsection{Applied forces}

The applied forces derive from gravity, suspensions and contact forces. The suspensions are classically defined as springs and dampers attached to specific points of the bodies. In the same manner, the contact forces are applied on the wheels. Their computation is explained further.

\subsection{The track model}

The track is represented by a finite element planar model, made up of 3 layers: the rail, the sleepers and the subgrade or foundation (Fig. 7). So far, only the vertical motion has been considered since the major contribution of ground vibration is induced by the vertical track deflection. Moreover, as symmetry is assumed, the track is condensed in the symmetry plane and embraces the 2 rails. The reduced central rail (Young modulus $E_{\mathrm{r}}$, density $\rho_{\mathrm{r}}$, geometrical moment of inertia $I_{\mathrm{r}}$ and section $A_{\mathrm{r}}$ for a single rail) consists of a succession of Euler beams, while the sleepers correspond to lumped masses of mass $m$, placed with a regular spacing $L$. The sleepers are connected by spring-damper systems to the rail (stiffness $k_{\mathrm{p}}$ and damping $d_{\mathrm{p}}$ representing a single railpad) and to the foundation (stiffness $k_{\mathrm{b}}$ and damping $d_{\mathrm{b}}$ representing the ballast). 


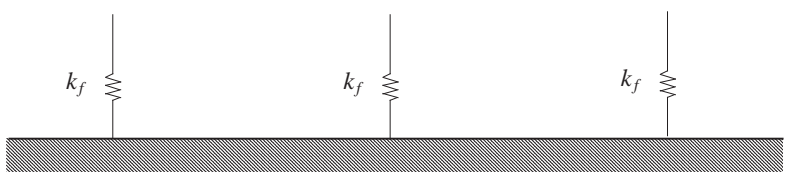

(a) Winkler model

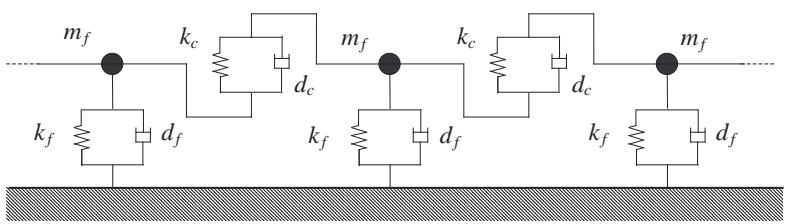

(b) CLM model

Figure 8. Foundation models (each discrete element is connected to each sleeper).

As indicated in the state of the art, the model retained to represent the track is the CLM (coupled lumped mass) model proposed in Kouroussis et al. (2011a,b). It permits to properly capture the track receptance even in presence of soft soils and therefore minimizes the error resulting from the hypothesis of track/soil decoupling. Compared to models based on the classical Winkler foundation representing one spring under each sleeper (Fig. 8a), it includes a better representation of the soil under the track through a layer of lumped masses of mass $m_{\mathrm{f}}$ placed below the sleepers (Fig. 8b), and viscoelastically connected to the bedrock (stiffness $k_{\mathrm{f}}$ and the damping $d_{\mathrm{f}}$ ) and to the surrounding foundation masses (damping $d_{\mathrm{c}}$ and stiffness $k_{\mathrm{c}}$ ). The values of the parameters of the CLM model $\left(m_{\mathrm{f}}, k_{\mathrm{f}}, d_{\mathrm{f}}, k_{\mathrm{c}}, d_{\mathrm{c}}\right)$ are calculated, through simple analytical relations (Kouroussis et al., 2011b), so as to match soil impedances issued from the FEM model of the soil $^{1}$.

Figure 9 illustrates the accuracy of the CLM approach, by comparing the track receptances of a specific high-speed track in Belgium, lying on various foundation models, for the 3 following cases

- the track model is included in the three-dimensional FEM model of the soil, which can be considered as the reference solution;

- the proposed track model with a foundation represented by a Winkler foundation;

- the proposed track model where the CLM model is used for the foundation.

Presented direct receptances are defined as frequency response functions between the vertical displacement of the rail above a sleeper and the vertical force applied at the same

\footnotetext{
${ }^{1}$ Impedances issued from experimental tests or from other models could be used equivalently.
}

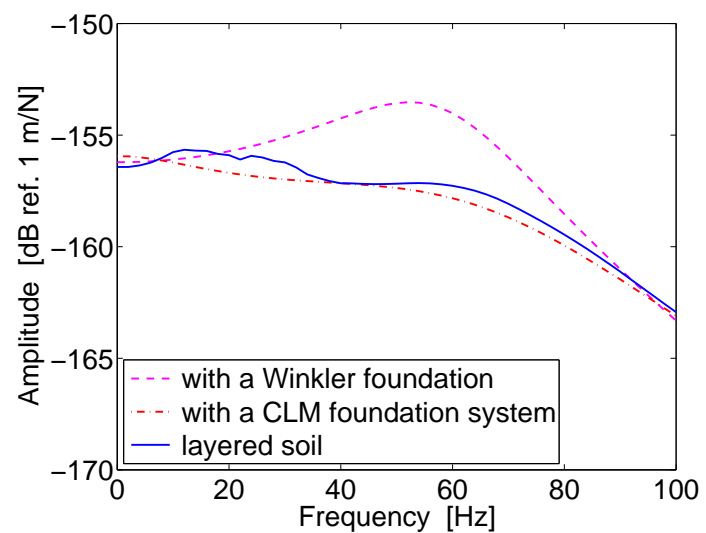

(a) Direct receptance

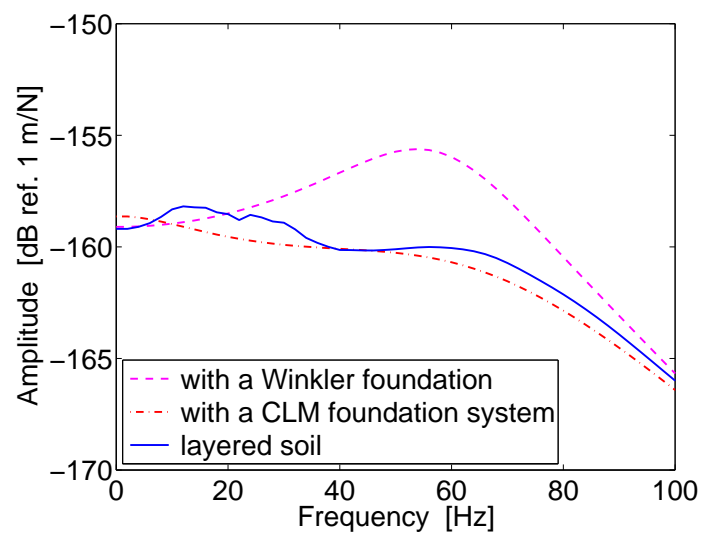

(b) Indirect receptance

Figure 9. Track receptances of the studied site (Mévernies - Belgium).

point. Indirect receptances correspond to rail displacement above the adjacent sleeper.

It appears that the CLM model properly captures the track receptances between $0 \mathrm{~Hz}$ and $100 \mathrm{~Hz}$, which is not the case of the Winkler foundation. A good agreement can be observed between the CLM and the reference case: the error remains below $1 \mathrm{~dB}$ which is well below the uncertainty range encountered in experimental receptances. The interest of this approach is certainly its ability to faithfully reproduce the track response with a limited number of degrees of freedom.

The size of the model depends on the track length required to get the requested level of accuracy, that is to say between 20 and $80 \mathrm{~m}$ (Kouroussis et al., 2010). Practically, this represents the flexible part of the track, surrounded by rigid parts, with a transition area along which the compliance progressively evolves. This assures a smooth loading of the soil and permits to manage vehicles longer than the considered track.

Concerning the degrees of freedom, the beam nodes introduce 2 degrees of freedom (vertical displacement and slope) while each lumped mass, representing either a sleeper or a foundation mass, introduces one degree of freedom. Knowing that 2 beam elements are defined between the sleepers, 
this leads, roughly speaking, to 6 degrees of freedom per sleeper, and consequently a few hundreds degrees of freedom for the track.

\section{Track interaction: wheel/rail contact forces}

The contact forces between the wheels and the rail allow coupling between the vehicle and the track. We have chosen to calculate this force through the well-known Hertz contact theory, stating that the normal contact force $N$ can be calculated from the penetration $d$ according to

$N=K_{\mathrm{Hz}} d^{3 / 2}$,

where the coefficient $K_{\mathrm{Hz}}$ depends only on the radii of curvature of the wheel and the rail profiles, and the elastic properties of the material of both bodies.

The penetration for each wheel $i$ depends on the vehicle and track states and is calculated from

$d_{\text {wheel }, i}=z_{\text {rail }}\left(x_{\text {wheel }, j}\right)-z_{\text {wheel }, i}+h\left(x_{\text {wheel }, i}\right)+R_{\text {wheel }, i}$

with

- $x_{\mathrm{wheel}, i}$ and $z_{\mathrm{wheel}, i}$ the coordinates of the centre of wheel $i$, depending on the configuration parameters of the vehicle;

- $z_{\text {rail }}\left(x_{\text {wheel }, j}\right)$ the height of the rail below wheel $i$, depending on the degrees of freedom of the track model, through the shape functions of the beam elements;

- $R_{\text {wheel }, i}$ the radius of wheel $i$;

- $h\left(x_{\text {wheel }, i}\right)$ the rail irregularity below wheel $i$, which can consist of local defects and/or overall track contribution like roughness (Kouroussis et al., 2010).

The action and reaction components of the contact force can then be applied to the multibody and track models. Let us note that, for the track, the force is transformed to nodal forces and torques, again through the shape functions of the beam element, calculated at the contact point.

Let us note that most of ground vibration models consider a linear relationship between the contact force and the penetration, neglecting the inherent non-linearity of the contact physics.

\section{Numerical framework}

The track/vehicle model explained in the previous sections has been implemented as a $\mathrm{C}++$ program based on the homemade EasyDyn library (Kouroussis et al., 2011c; Verlinden et al., 2013).

The equations of motion and of the vehicle (Eq. 1) and of the track (Eq. 2), are rewritten in the following residual form

$\boldsymbol{f}(\boldsymbol{q}, \dot{\boldsymbol{q}}, \ddot{\boldsymbol{q}}, t)=\left\{\begin{array}{c}\mathbf{M}_{\mathrm{v}} \cdot \ddot{\boldsymbol{q}}_{\mathrm{v}}+\boldsymbol{h}_{\mathrm{v}}\left(\boldsymbol{q}_{\mathrm{v}}, \dot{\boldsymbol{q}}_{\mathrm{v}}, t\right)-\boldsymbol{f}_{\mathrm{v}}\left(\boldsymbol{q}_{\mathrm{v}}, \boldsymbol{q}_{\mathrm{t}}, t\right) \\ \mathbf{M}_{\mathrm{t}} \cdot \ddot{\boldsymbol{q}}_{\mathrm{t}}+\mathbf{C}_{\mathrm{t}} \cdot \dot{\boldsymbol{q}}_{\mathrm{t}}+\mathbf{K}_{\mathrm{t}} \cdot \boldsymbol{q}_{\mathrm{t}}-\boldsymbol{f}_{\mathrm{t}}\left(\boldsymbol{q}_{\mathrm{v}}, \boldsymbol{q}_{\mathrm{t}}, t\right)\end{array}\right\}=0$ where the global vector of configuration parameters $\boldsymbol{q}$ results from the concatenation of the vehicle and track configuration parameters

$\boldsymbol{q}=\left\{\begin{array}{c}\boldsymbol{q}_{\mathrm{v}} \\ \boldsymbol{q}_{\mathrm{t}}\end{array}\right\}$.

When rewritten in this form, the equations can be integrated by the routines provided by the sim module, which implement the so-called Newmark-1/4 method. The latter is known to not introduce any numerical damping which is an advantage in the considered application. Numerical damping is anyway unnecessary as we deal with ordinary differential equations.

The vehicle is a multibody system and its equations of motion are computed from the routines offered by the mbs module. This assumes that the user provides two routines implementing on the one hand the kinematics of the multibody system and, on the other hand, the forces exerted on each body, corresponding in our case to the gravity, the suspension forces and the contact forces. Let us recall that concerning the kinematics, the velocities, accelerations and partial velocities are generated symbolically by the script CAGeM accompanying the $\mathrm{C}++$ library of EasyDyn.

The equations of motion of the track (Eq. 2) are simple and are coded directly in $\mathrm{C}++$ by using the classical assembly techniques.

The computer implementation is summarized in Fig. 10 . Let us note that, thanks to the visu module, shapes can be attached to bodies, in order to visualize the motion of the system.

\section{Soil simulation}

The simulation of the vehicle/track subsystem provides the time history of the ground forces, defined as the visco-elastic action of the ballast on the subgrade. These forces are used in the second subproblem, managed under the finite element software ABAQUS which computes the free field response.

The finite element model of the soil is out of the scope of this paper, a detailed description of the finite element model being available in Kouroussis et al. (2010, 2012a). Let us mention anyway that

- only a half soil is considered due to the assumed leftright symmetry;

- the forces are not applied on nodes but on rigid surfaces corresponding to the area covered by the sleepers;

- the inner part of the model consists of one quarter of a sphere and defines the specific geometry of the considered track;

- a dedicated script generates the outer part consisting of a transition spherical slice with progressive element sizes, surrounded by the infinite elements. 


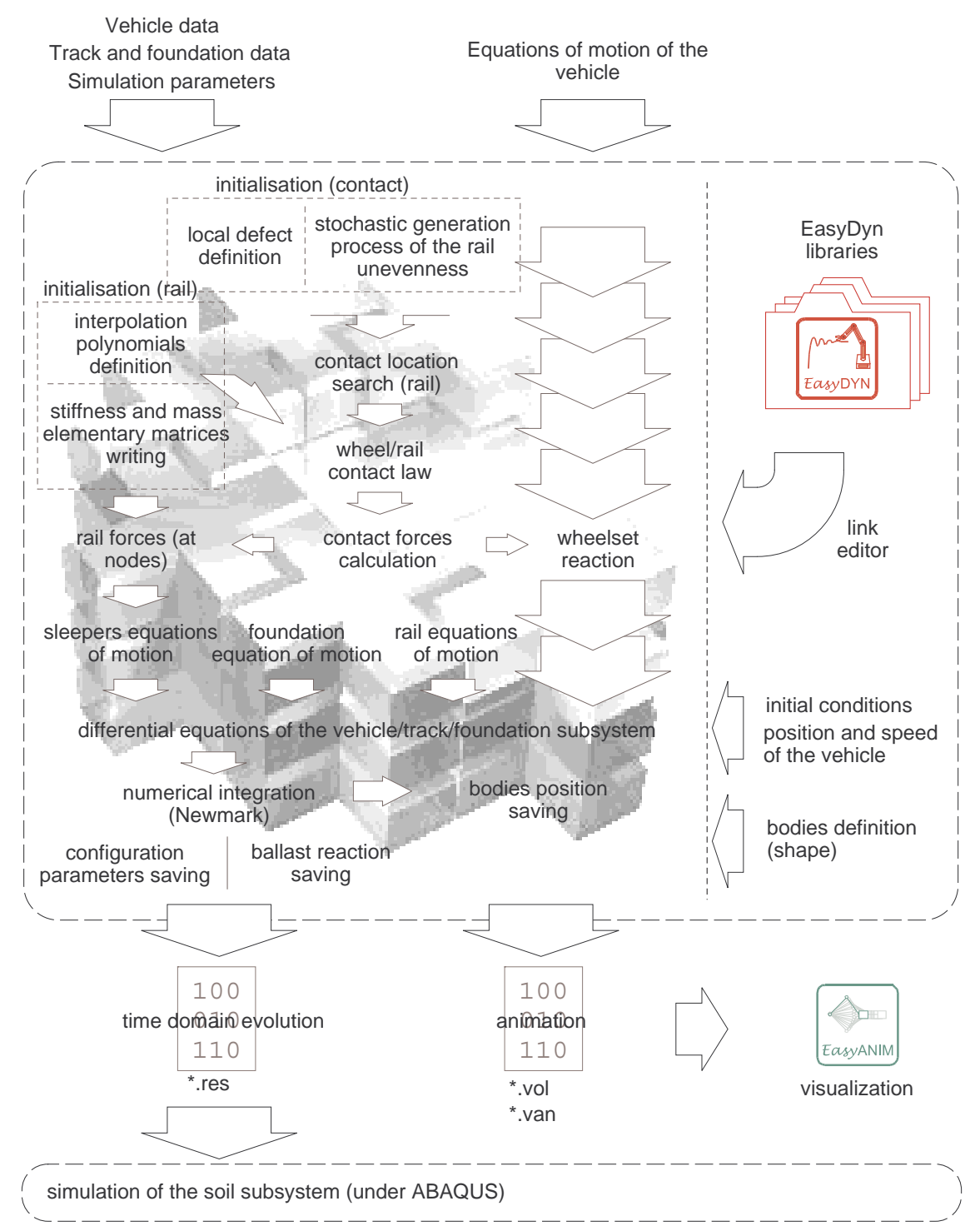

Figure 10. Computer implementation of the vehicle/track model.

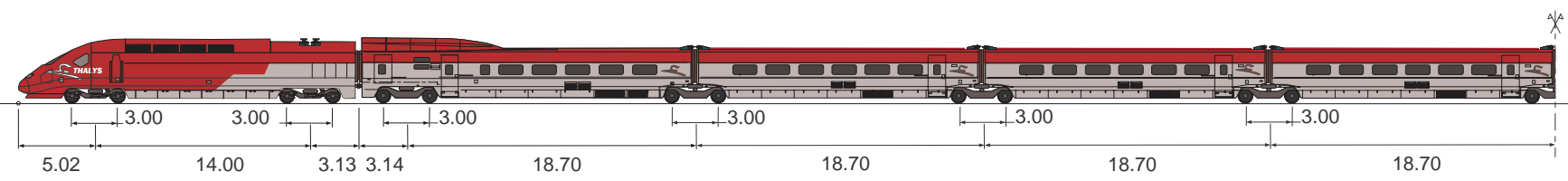

Figure 11. Thalys HST dimensions

\section{Example: the Thalys high-speed train}

\subsection{Description of the model}

Thalys trains are designed to operate over the French, Belgian, German and Dutch networks and therefore ensure the interconnection between the different high-speed lines. The high-speed vehicle studied in this work stems from the same generation as the French TGV Atlantique with some mi- nor differences in the dynamical and geometrical parameters. The vehicle data were supplied by the Belgian railway operator. Figure 11 shows the configuration and the dimensions of these trainsets, consisting of 2 locomotives and 8 carriages, with a total length of $200 \mathrm{~m}$. The two locomotives are supported by two bogies. Instead of the conventional bogie configuration of two-to-a-car, the carriage bogies are placed half under one car and half under the next, with the exception of 


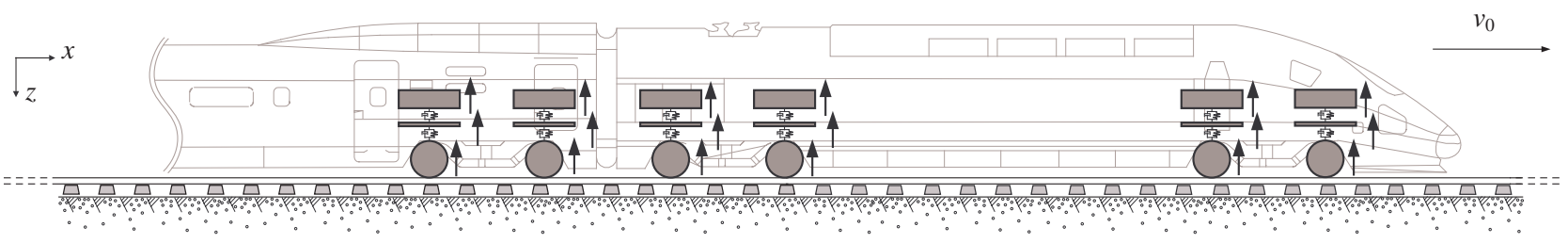

(a) Old model

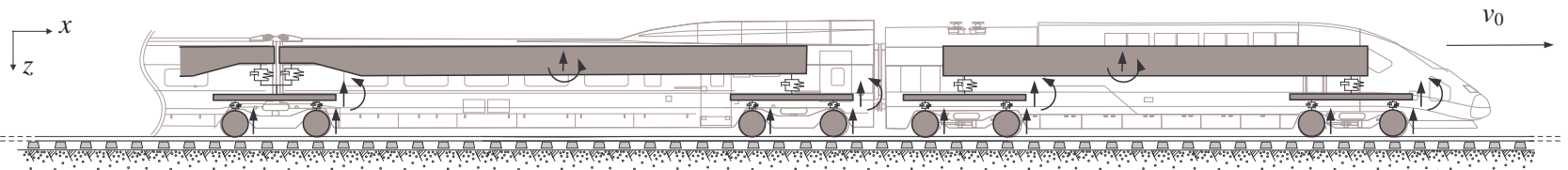

(b) New model

Figure 12. Studied multibody models for the vehicle.

Table 1. Dynamic parameters of Thalys HST - unladen weight.

\begin{tabular}{lrrr}
\hline & $\begin{array}{r}\text { Bogie } \\
\text { Y230A }\end{array}$ & $\begin{array}{r}\text { Bogie } \\
\text { Y237A }\end{array}$ & $\begin{array}{r}\text { Bogie } \\
\text { Y237B }\end{array}$ \\
\hline Carbody mass $m_{\mathrm{c}}[\mathrm{kg}]$ & 26721 & 14250 & 20426 \\
Carbody pitch moment of inertia $I_{\mathrm{c}}\left[\times 10^{6} \mathrm{~kg} \mathrm{~m}^{2}\right]$ & 1.15 & 0.61 & 0.88 \\
Bogie mass $m_{\mathrm{b}}[\mathrm{kg}]$ & 3261 & 15650 & 8156 \\
Bogie pitch moment of inertia $I_{\mathrm{b}}\left[\mathrm{kg} \mathrm{m}^{2}\right]$ & 2870 & 13750 & 7185 \\
Wheelset mass $m_{0}[\mathrm{~kg}]$ & 2009 & 2050 & 2009 \\
Primary suspension stiffness $k_{1}\left[\mathrm{MN} \mathrm{m}^{-1}\right]$ & 2.09 & 1.63 & 2.09 \\
Primary suspension damping $d_{1}\left[\mathrm{kNs} \mathrm{m}^{-1}\right]$ & 40 & 40 & 40 \\
Secondary suspension stiffness $k_{2}\left[\mathrm{MN} \mathrm{m}^{-1}\right]$ & 2.45 & 0.93 & 2.45 \\
Secondary suspension damping $d_{2}\left[\mathrm{kNs} \mathrm{m}^{-1}\right]$ & 40 & 40 & 40 \\
\hline
\end{tabular}

the side carriage bogies, which connect the power carriages (at the outer extremities of the train) to the main passenger carriages (in the centre of the train). The unladen mass is close to 386 tonnes, while the nominal loading is worth 439 tonnes.

Three bogie types are used in this vehicle:

- the Y230A motor bogie equipping the locomotives;

- the Y237 trailing bogie: variant A for the side carriages and variant $\mathrm{B}$ for the other ones.

An SR 10 pneumatic air-sprung suspension is used as the secondary suspension of the trailing bogies while the coil spring is preferred for the primary suspension. For the Y230A, classical rubber sandwich block (coil) spring is used for the primary (secondary) suspension. Table 1 summarizes the dynamic parameters of the bogies in terms of mass, stiffness and damping.

The Thalys HST has already been studied by the authors (Kouroussis et al., 2011e). However, due to a lack in the vehicle data that we were able to collect, the pitch motion of the bogie and carbodies was neglected. The bogie and the carbody were actually replaced by a front and a rear lumped mass whose only bounce motion was taken into ac- count (Fig. 12a). The present model consists of a succession of carbodies, bogies and wheelsets involving 2 degrees of freedom (bounce and pitch) for each carbody/bogie and 1 degree of freedom (bounce) for each wheelset (Fig. 12b).

The Thalys HST, in its general configuration consists of a succession of one locomotive, one side carriage, six central carriages, one side carriage and finally one locomotive, with a total of 72 degrees of freedom. The relevant geometrical data of the train are specified in Table 2.

If the vehicle rides at velocity $v_{0}$, the position matrices relative to the first locomotive are written

$$
\begin{aligned}
\mathbf{T}_{0, \text { carbody }} & =\mathbf{T}^{\text {disp }}\left(v_{0} t, 0, q_{1,1}\right) \cdot \mathbf{T}^{\text {rot. } y}\left(q_{1,2}\right) \\
\mathbf{T}_{0, \text { front bogie }} & =\mathbf{T}^{\text {disp }}\left(v_{0} t+l_{\mathrm{b}} / 2,0, q_{1,3}\right) \cdot \mathbf{T}^{\text {rot. } y}\left(q_{1,4}\right) \\
\mathbf{T}_{0, \text { rear bogie }} & =\mathbf{T}^{\text {disp }}\left(v_{0} t-l_{\mathrm{b}} / 2,0, q_{1,5}\right) \cdot \mathbf{T}^{\text {rot. } y}\left(q_{1,6}\right) \\
\mathbf{T}_{0, \text { first wheel }} & =\mathbf{T}^{\text {disp }}\left(v_{0} t+l_{\mathrm{b}} / 2+l_{\mathrm{w}} / 2,0, q_{1,7}\right) \\
\mathbf{T}_{0, \text { second wheel }} & =\mathbf{T}^{\text {disp }}\left(v_{0} t+l_{\mathrm{b}} / 2-l_{\mathrm{w}} / 2,0, q_{1,8}\right) \\
\mathbf{T}_{0, \text { third wheel }} & =\mathbf{T}^{\text {disp }}\left(v_{0} t-l_{\mathrm{b}} / 2+l_{\mathrm{w}} / 2,0, q_{1,9}\right) \\
\mathbf{T}_{0, \text { fourth wheel }} & =\mathbf{T}^{\text {disp }}\left(v_{0} t-l_{\mathrm{b}} / 2-l_{\mathrm{w}} / 2,0, q_{1,10}\right)
\end{aligned}
$$

where $q_{1, i}$ are the 10 configuration parameters of the locomotive, with $q_{1,1}$ and $q_{1,2}$ the bounce and pitch motions of the carbody, $q_{1,3}$ and $q_{1,4}\left(q_{1,5}\right.$ and $\left.q_{1,6}\right)$ the bounce and pitch 
Table 2. Geometric parameters of Thalys HST.

\begin{tabular}{lcc}
\hline Parameter & Symbol & Value (m) \\
\hline Distance between bogies on locomotive & $l_{\mathrm{b}}$ & 14 \\
Bogie wheelbase & $l_{\mathrm{b}}$ & 3 \\
Distance between locomotive COM and side carriage COM & $d_{\mathrm{lb}}$ & 23.12 \\
Central carriage length & $b$ & 18.7 \\
\hline
\end{tabular}

Table 3. Studied site parameters (Mévernies - Belgium).

\begin{tabular}{|c|c|c|c|c|}
\hline \multicolumn{5}{|c|}{ Track parameters } \\
\hline $\begin{array}{c}E_{\mathrm{r}} \\
210 \mathrm{GPa}\end{array}$ & $\begin{array}{c}I_{\mathrm{r}} \\
3055 \mathrm{~cm}^{4}\end{array}$ & $\begin{array}{c}\rho_{\mathrm{r}} \\
7850 \mathrm{~kg} \mathrm{~m}^{-3}\end{array}$ & $\begin{array}{c}A_{\mathrm{r}} \\
63.9 \mathrm{~cm}^{2}\end{array}$ & $\begin{array}{c}d \\
0.6 \mathrm{~m}\end{array}$ \\
\hline $\begin{array}{c}k_{\mathrm{p}} \\
120 \mathrm{MNm}^{-1}\end{array}$ & $\begin{array}{c}d_{\mathrm{p}} \\
4 \mathrm{kNs} \mathrm{m}^{-1}\end{array}$ & $\begin{array}{c}k_{\mathrm{b}} \\
47 \mathrm{MNm}^{-1}\end{array}$ & $\begin{array}{c}d_{\mathrm{b}} \\
72 \mathrm{kNs} \mathrm{m}^{-1}\end{array}$ & $\begin{array}{c}m \\
150 \mathrm{~kg}\end{array}$ \\
\hline \multicolumn{5}{|c|}{ Soil parameters } \\
\hline layer & $d$ & $E$ & $\rho$ & $v$ \\
\hline 1 & $2.7 \mathrm{~m}$ & $129 \mathrm{MPa}$ & $1600 \mathrm{~kg} \mathrm{~m}^{-3}$ & 0.3 \\
\hline 2 & $3.9 \mathrm{~m}$ & $227 \mathrm{MPa}$ & $2000 \mathrm{~kg} \mathrm{~m}^{-3}$ & 0.3 \\
\hline 3 & $\infty$ & $659 \mathrm{MPa}$ & $2000 \mathrm{~kg} \mathrm{~m}^{-3}$ & 0.3 \\
\hline $\begin{array}{c}m_{\mathrm{f}} \\
460 \mathrm{~kg}\end{array}$ & $\begin{array}{c}k_{\mathrm{f}} \\
40 \mathrm{MN} \mathrm{m}^{-1}\end{array}$ & $\begin{array}{c}d_{\mathrm{f}} \\
426 \mathrm{kNs} \mathrm{m}^{-1}\end{array}$ & $\begin{array}{c}k_{\mathrm{c}} \\
63 \mathrm{MNm}^{-1}\end{array}$ & $\begin{array}{c}d_{\mathrm{c}} \\
-73 \mathrm{kNs} \mathrm{m}^{-1}\end{array}$ \\
\hline
\end{tabular}

motions of the front (rear) bogie, and $q_{1,7}$ to $q_{1,10}$ the bounce motions of the wheelsets.

For the side carriages, we get

$$
\begin{aligned}
\mathbf{T}_{0, \text { carbody }}= & \mathbf{T}^{\operatorname{disp}}\left(v_{0} t-d_{\mathrm{lb}}, 0, q_{\mathrm{s}, 1}\right) \cdot \mathbf{T}^{\text {rot. } y}\left(q_{\mathrm{s}, 2}\right) \\
\mathbf{T}_{0, \text { front bogie }}= & \mathbf{T}^{\operatorname{disp}}\left(v_{0} t-d_{\mathrm{lb}}+l_{\mathrm{b}} / 2,0, q_{\mathrm{s}, 3}\right) \\
& \cdot \mathbf{T}^{\text {rot. } y}\left(q_{\mathrm{s}, 4}\right) \\
\mathbf{T}_{0, \text { rear bogie }}= & \mathbf{T}^{\operatorname{disp}}\left(v_{0} t-d_{\mathrm{lb}}-l_{\mathrm{b}} / 2,0, q_{\mathrm{s}, 5}\right) \\
& \cdot \mathbf{T}^{\operatorname{rot} y}\left(q_{\mathrm{s}, 6}\right) \\
\mathbf{T}_{0, \text { first wheel }}= & \mathbf{T}^{\operatorname{disp}}\left(v_{0} t-d_{\mathrm{lb}}+l_{\mathrm{b}} / 2+l_{\mathrm{w}} / 2,0, q_{\mathrm{s}, 7}\right) \\
\mathbf{T}_{0, \text { second wheel }}= & \mathbf{T}^{\operatorname{disp}}\left(v_{0} t-d_{\mathrm{lb}}+l_{\mathrm{b}} / 2-l_{\mathrm{w}} / 2,0, q_{\mathrm{s}, 8}\right) \\
\mathbf{T}_{0, \text { third wheel }}= & \mathbf{T}^{\operatorname{disp}}\left(v_{0} t-d_{\mathrm{lb}}-l_{\mathrm{b}} / 2+l_{\mathrm{w}} / 2,0, q_{\mathrm{s}, 9}\right) \\
\mathbf{T}_{0, \text { fourth wheel }}= & \mathbf{T}^{\operatorname{disp}}\left(v_{0} t-d_{\mathrm{lb}}-l_{\mathrm{b}} / 2-l_{\mathrm{w}} / 2,0, q_{\mathrm{s}, 10}\right)
\end{aligned}
$$

where $q_{\mathrm{s}, i}(i=1 \mapsto 10)$ have the same meaning as $q_{1, i}$ for the locomitve.

There is only one bogie per central carriage, which is the rear one, the front one being kinematically attached to the previous carriage. The corresponding position matrices of the $j$-th central carriage then read

$$
\begin{aligned}
\mathbf{T}_{0, \text { carbody j }}= & \mathbf{T}^{\text {disp }}\left(v_{0} t-d_{\mathrm{lb}}-l_{\mathrm{b}} / 2-(2 j-1) b / 2,0, q_{c j, 1}\right) \\
& \cdot \mathbf{T}^{\text {rot. } y}\left(q_{c j, 2}\right) \\
\mathbf{T}_{0, \text { rear bog. } \mathrm{j}}= & \mathbf{T}^{\text {disp }}\left(v_{0} t-d_{\mathrm{lb}}-l_{\mathrm{b}} / 2-j b, 0, q_{c j, 3}\right) \\
& \cdot \mathbf{T}^{\text {rot. } y}\left(q_{c j, 4}\right) \\
\mathbf{T}_{0,1 \mathrm{t} \text { wheel j }}= & \mathbf{T}^{\text {disp }}\left(v_{0} t-d_{\mathrm{lb}}-l_{\mathrm{b}} / 2-j b+l_{\mathrm{w}} / 2,0, q_{c j, 5}\right) \\
\mathbf{T}_{0,2 \text { nd wheel j }}= & \mathbf{T}^{\text {disp }}\left(v_{0} t-d_{\mathrm{lb}}-l_{\mathrm{b}} / 2-j b-l_{\mathrm{w}} / 2,0, q_{c j, 6}\right)
\end{aligned}
$$

with $q_{c j, i}(i=1 \mapsto 6$ and $j=1 \mapsto 6)$ the configuration parameters of the carriage, defined in the same manner as previously.

The track model involves 160 sleepers. The parameters of the track and of the CLM model used to represent the foundation are pointed out in Table 3. The CLM parameters issue from the identification of the foundation receptance with respect to a 3-D FEM model of the soil comprising 3 layers. For each layer, the depth $d$, the Young modulus $E$, the density $\rho$ and the Poisson's number $v$ are also given in Table 3 . Let us note that the damping $d_{\mathrm{c}}$ is negative, so as to properly capture the ground wave propagation delay, also called "tau effect".

\subsection{Simulation results}

\subsubsection{Studied configurations}

In the next sections, the results provided by three different models are compared

- The initial model Kouroussis et al. (2011e), without the pitch motion of bogies and carbodies and a Winkler foundation for the track subgrade. It is denoted by model A.

- An intermediary model, with the same vehicle as model A but where the CLM model has been adopted for the track subgrade. It is denoted by model B. 


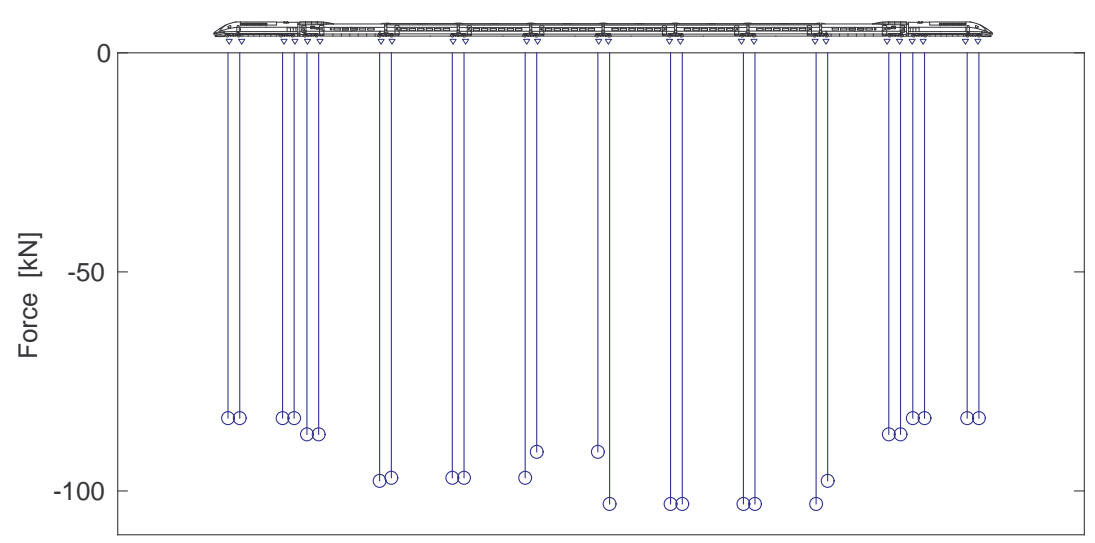

(a) Static axle load acting on the track
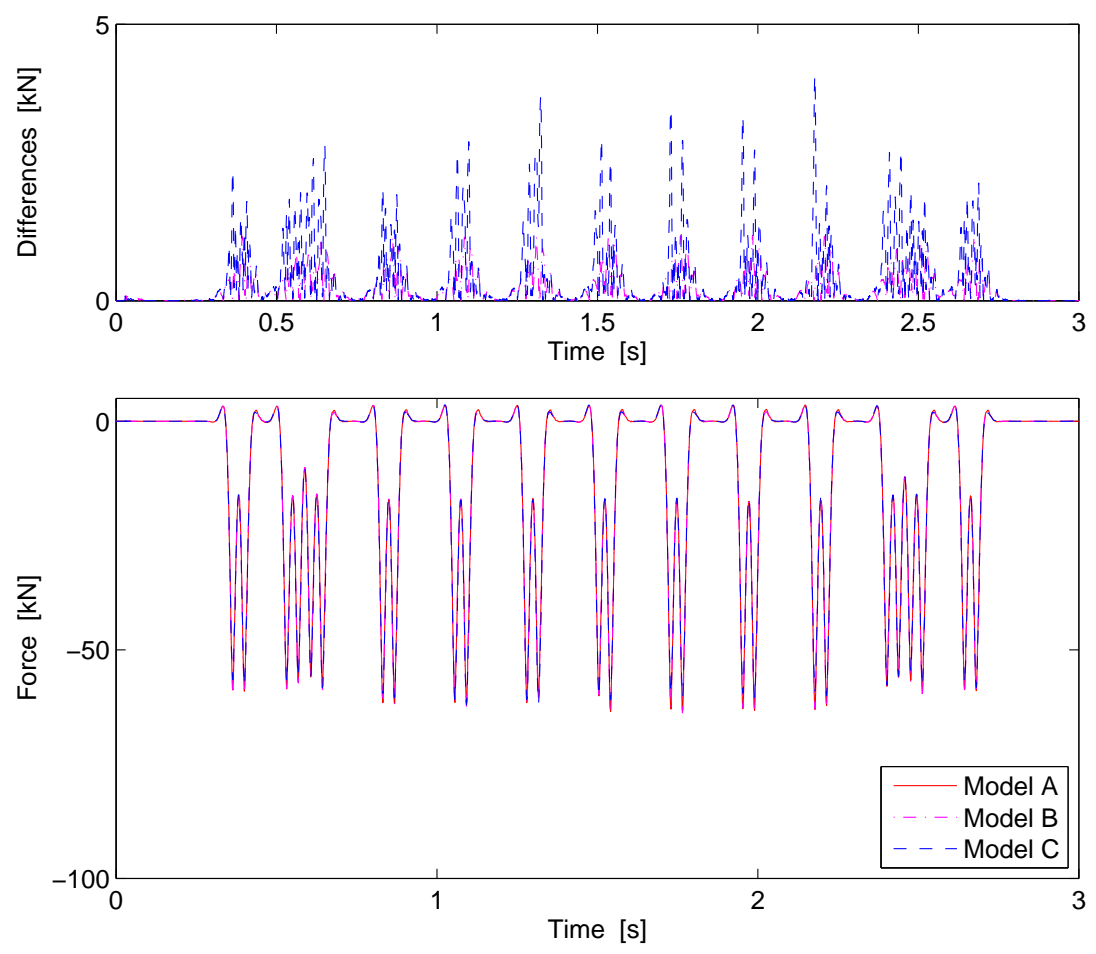

(b) Ballast reaction used as input in the soil model

Figure 13. Time history of track/foundation forces for each model.

- The complete model, denoted by model C, as described in this paper with the CLM model and the pitch motion of bogies and carbodies.

In all cases, the train speed is worth $v_{0}=300 \mathrm{kmh}^{-1}$ and the rail irregularity is calculated for a rail quality of 6 (Garg and Dukkipati, 1984; Kouroussis et al., 2012a).

\subsubsection{Forces on the track}

Figure $13 b$ shows the time history of the force exerted by the track on the soil at the centre of the model, for each model. In addition to these curves, the difference of force magnitudes provided by models B and C, compared to model A, is presented. This force, along with the ones under the other sleepers, is used as input in the FEM model of the soil to study the wave propagation. The plot is to compare with the one of Fig. 13a which shows the static load on the track, in function of a pseudo-time corresponding to the distance divided by the velocity. The figures show how the track distributes the contact forces through the sleepers.

It turns out that there is no significant difference between the models, especially between model A and model B. The major difference appears when the deflection is maximum and reaches about $2 \%$ between models $\mathrm{A}$ and $\mathrm{B}$ but more 


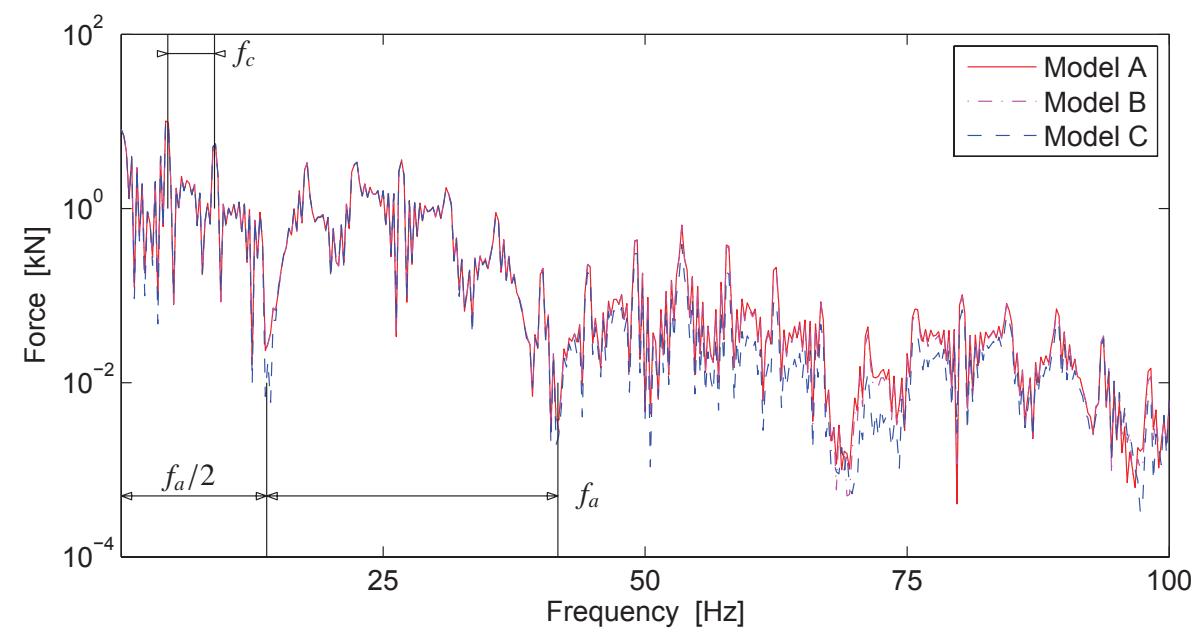

Figure 14. Frequency content of ballast reaction force for each model.

than $5 \%$ between models $\mathrm{A}$ and $\mathrm{C}$. This is confirmed by the corresponding frequency content, illustrated in Fig. 14. The latter reveals the usual peaks, related to the carriage passage excitation mechanisms at frequency $f_{\mathrm{c}}=v_{0} / l_{\mathrm{b}}=4.5 \mathrm{~Hz}$ modulated in amplitude by the fundamental axle passage frequency $f_{\mathrm{a}}=v_{0} / l_{\mathrm{w}}=27.8 \mathrm{~Hz}$. The magnitudes at frequency $\frac{k}{2} f_{\mathrm{a}}(k=1,3,5, \ldots)$ are completely suppressed.

The analysis shows that on one hand the benefit brought by the CLM model is not significant, due to the fact that the soil is relatively rigid. On the other hand, the differences observed with model $\mathrm{C}$, although limited, indicate the importance of a careful vehicle modelling in the prediction of railway induced ground vibrations.

\subsubsection{Ground vibrations}

Figure 15 shows the time history of the vertical ground velocity at $9 \mathrm{~m}$ from the track, resulting from the application of the ballast reaction forces, obtained from the simulation of each vehicle/track model, on the 3-D FEM model of the soil. The figure also includes the experimental results presented in a previous work (Kouroussis et al., 2011e). The corresponding weighted severity can be found in Fig. 16, as defined in the DIN 4150 part 2 standard (Deutsches Institut für Normung, 1999). This indicator provides a quantification of the maximum vibratory dose felt by residents, and presents an interesting basis for drawing a parallel between discomfort and ground vibrations. Finally, Fig. 17 shows the frequency content of the ground velocity and indicates the maximum amplitude at $26 \mathrm{~Hz}$. The latter is imposed by a resonance-like phenomenon, where the soil surface vibrates in phase with the vertical loading at a frequency corresponding to

$f_{\text {layer }}=\frac{c_{P}}{4 d}$ with $c_{P}$ the compression wave velocity of the first layer and $d$ its depth.

The following observations are noteworthy:

- The comparison of the results obtained from models A, $\mathrm{B}$ and $\mathrm{C}$ leads to the same conclusions as in the previous section. The difference between models A/B and C is clearly observed on the weighted severity, at the beginning and end of the ground vibration. In the same way, the frequency contents differ in mid and high frequencies. Note that the experimental values at $23 \mathrm{~m}$ have greater amplitude than those at 25 and $18 \mathrm{~m}$, whose origin is unfortunately unknown.

- Figures 15 and 16 show a good agreement between predicted and experimental ground vibrations, which validates the hypothesis made by the authors concerning the track/soil decoupling when the soil is sufficiently rigid with respect to the ballast (Kouroussis et al., 2012a). It must however be mentioned that the vibration peaks predicted in the frequency ranges $20-30 \mathrm{~Hz}$ and 50 $60 \mathrm{~Hz}$ (Fig. 17) are larger than their experimental counterparts. At high frequencies, the gap is explained by the adopted material damping in the soil model: a time domain simulation imposes a viscous damping although the hysteretic damping better corroborates for soil motion since it does not significantly depend on the frequency of motion.

As a final result, Fig. 18 shows how the the peak particle velocity PPV and the $\mathrm{KB}_{F \text {, max }}$ indicators evolve with the distance from the track $d$. The second indicator is defined as the maximum of the weighted severity. The attenuation is identical for the three models, when fitted according to a simple 


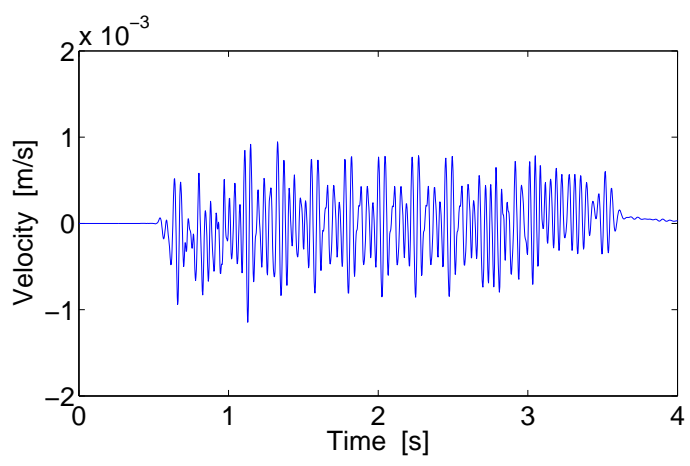

(a) Model A

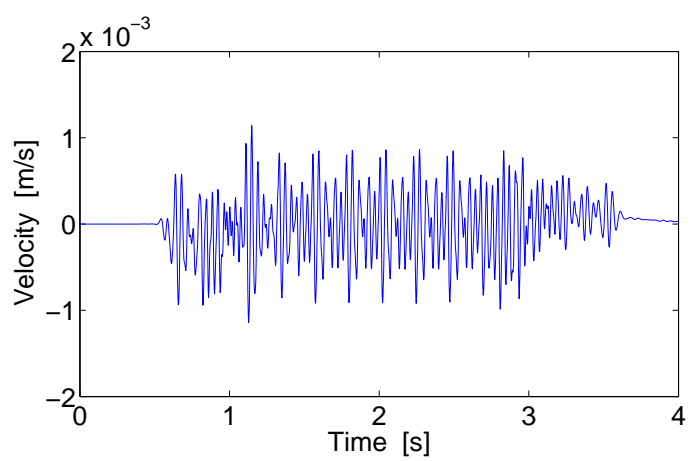

(c) Model C

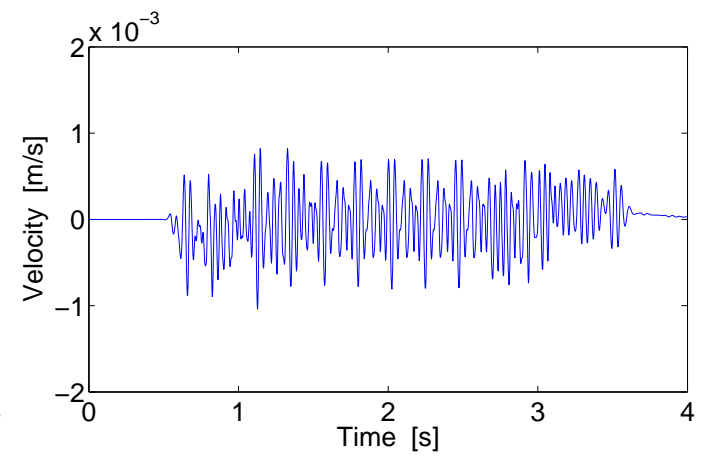

(b) Model B

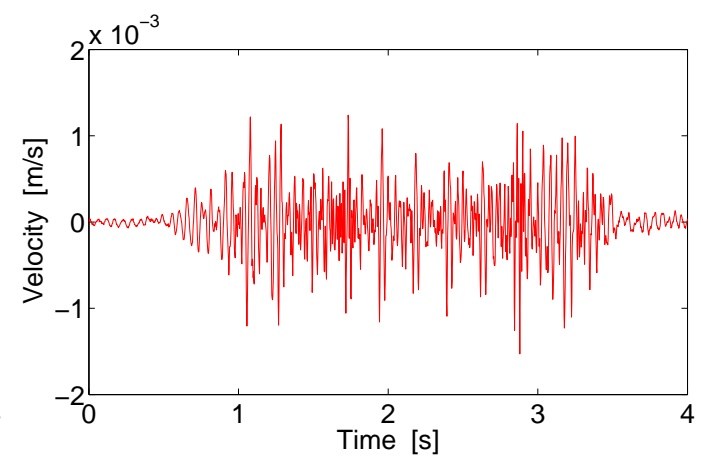

(d) Experimental

Figure 15. Predicted and measured time history of vertical ground velocity at $9 \mathrm{~m}$ from the track.

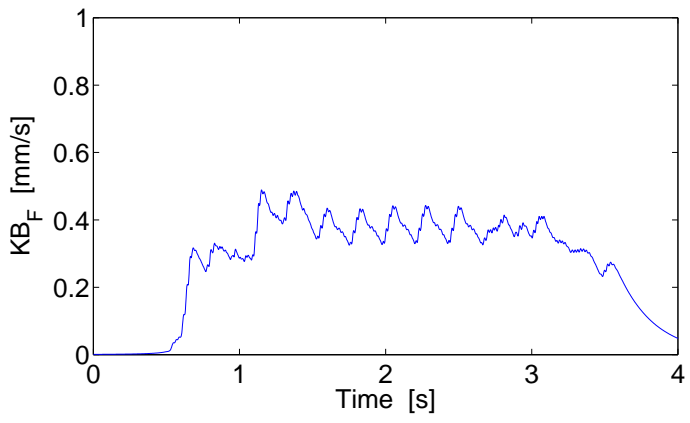

(a) Model A

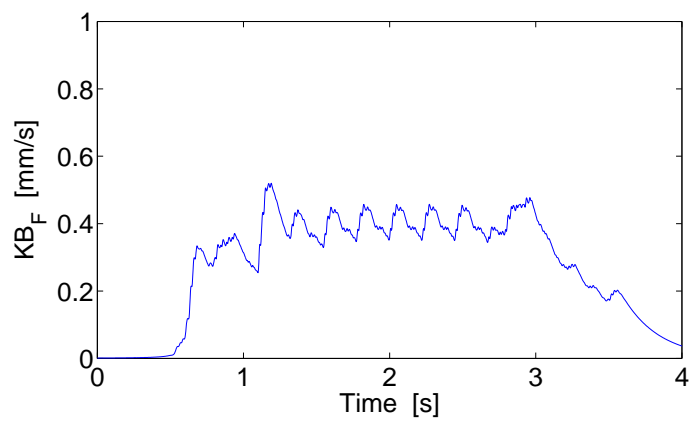

(c) Model C

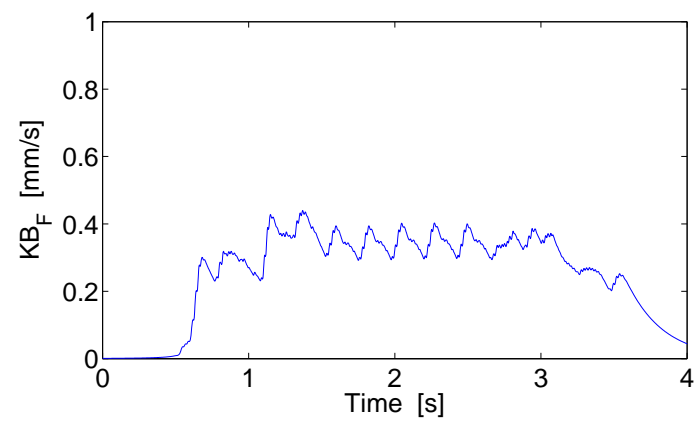

(b) Model B

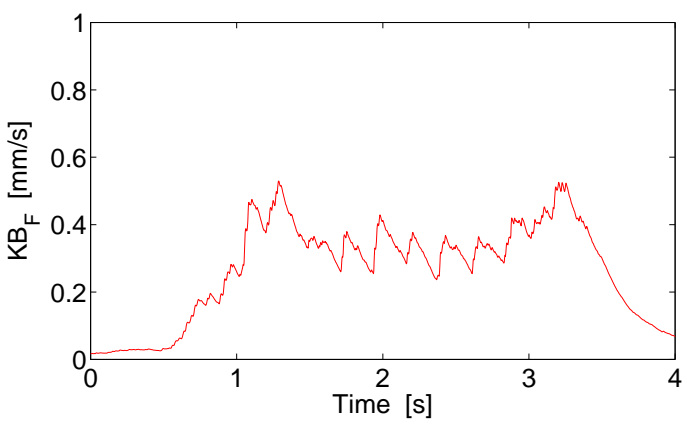

(d) Experimental

Figure 16. Predicted and measured weighted severity of vertical ground velocity at $9 \mathrm{~m}$ from the track. 


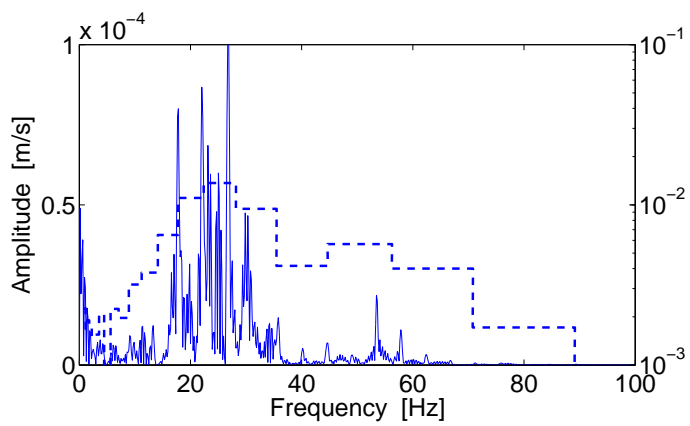

(a) Model A

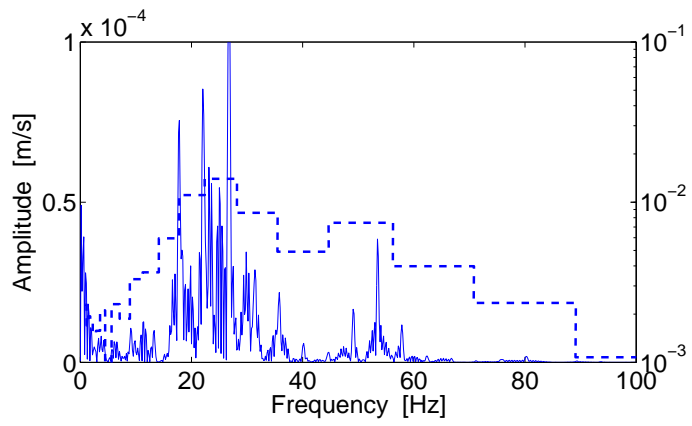

(c) Model C

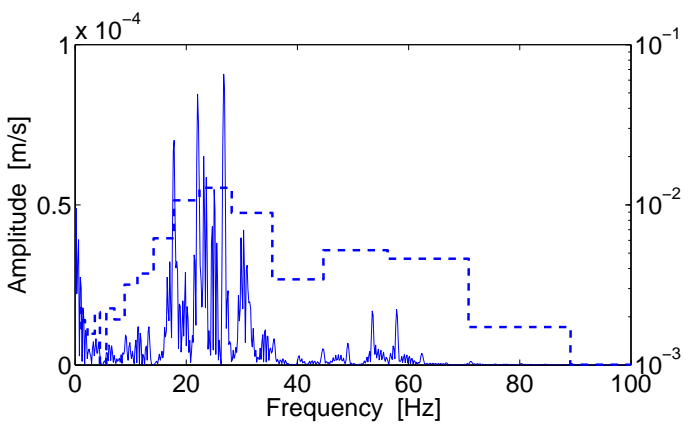

(b) Model B

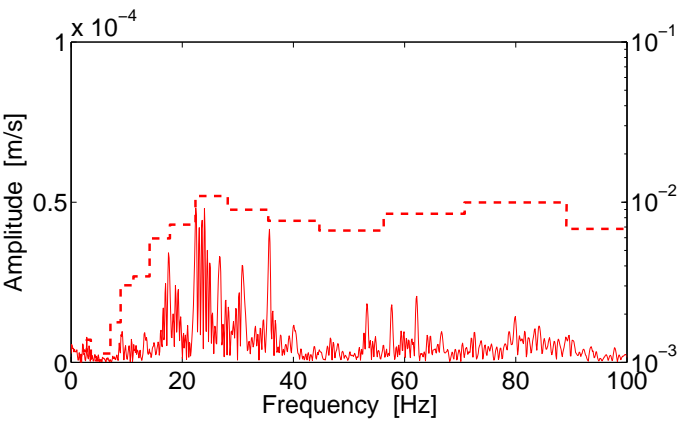

(d) Experimental

Figure 17. Predicted and measured frequency content (spectra in solid line and one-third octave band in dashed line) of vertical ground velocity at $9 \mathrm{~m}$ from the track.

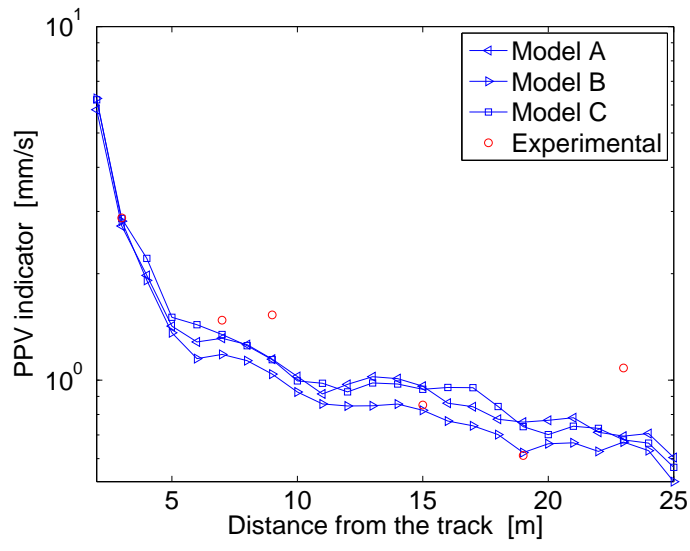

(a) Peak particle velocity comparison

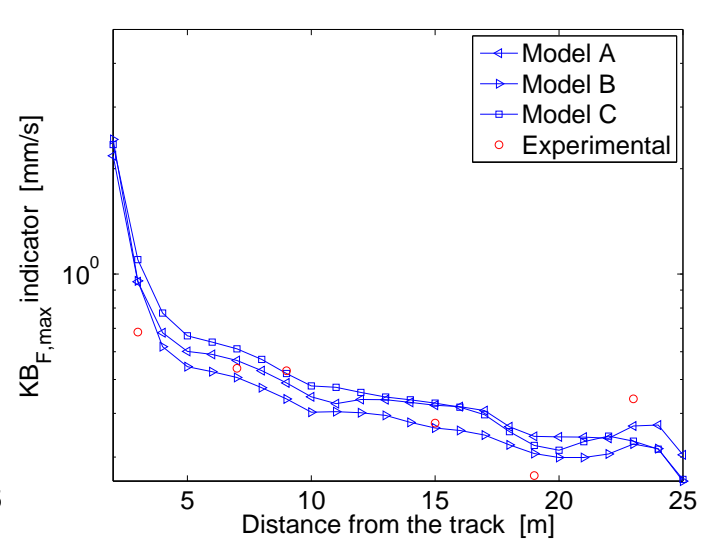

(b) $K B_{F, \text { max }}$ comparison

Figure 18. Overview of the ground vibration level difference for various distances from the track.

power-law function

$\begin{aligned} \mathrm{PPV} & \propto d^{-0.7} \\ \mathrm{~KB}_{F, \max } & \propto d^{-0.5} .\end{aligned}$

The comparison with experimental results is not bad, with the exception of the point at $23 \mathrm{~m}$ from the track, where the experimental level is suspiciously greater than the ones at 15 and $18 \mathrm{~m}$.

\section{Conclusions}

In this paper, we have presented the framework that we have developed for predicting the vibrations induced by railway transportation. The vibrations find their origin on the one hand on the nature of the track, discretely supported at the sleepers, and on the other hand in the irregularity of the rail surface. The proposed framework first considers the vehicle/track model mixing the multibody model of the vehicle and the finite element model of the track, coupled to each 
other through the wheel/rail contact. Only the motion in the vertical plane is considered, assuming a total symmetry between left and right rails. This first step is implemented on the basis of the home-made C++ library EasyDyn and produces a time history record of the forces exerted by the ballast on the foundation, which are then applied to a full 3-D FEM model of the soil. The latter is managed by the commercial software ABAQUS and involves finite elements to represent the unbounded nature of the considered domain. Again, symmetry is assumed betwen left and right parts so that only a half domain is defined.

With respect to previous publications, the model of the vehicle no longer consists of a succession of travelling masses but considers the carbodies and bogies as actual bodies, undergoing namely a pitch motion. The interest of the coupled lumped mass model has also been emphasized. The latter offers a better representation of the foundation contribution in the track model, and extends the application range of the approach, based on a decoupling of the vehicle/track and soil subsystems.

The potential applications of the model are illustrated on the example of the Thalys high-speed train, riding at $300 \mathrm{~km} \mathrm{~h}^{-1}$ on the Belgian site of Mévergnies. A good agreement is observed between experimental and predicted track and ground vibrations. In this particular case, the CLM model does not bring any significant improvement due to the relatively high stiffness of the soil. The new vehicle model, consisting essentially of the pitch motion of the bodies, introduces light changes in the response.

Although the model of the vehicle remains simple, the presented methodology does no longer suffer any limitations for the extension of the model to dissymetric cases or the effect of lateral contributions.

Edited by: O. Brüls

Reviewed by: J. Escalona and one anonymous referee

\section{References}

Anantharam, M. and Hiller, M.: Numerical Simulation of Mechanical Systems Using Methods for Differential-Algebraic Equations, Int. J. Num. Meth. Eng., 21, 1531-1542, 1991.

Bauchau, O.: Flexible Multibody Dynamics, Springer, Dordrecht, The Netherlands, 2011.

Connolly, D., Giannopoulos, A., and Forde, M. C.: Numerical modelling of ground borne vibrations from high speed rail lines on embankments, Soil Dyn. Earthq. Eng., 46, 13-19, 2013.

Costa, P., Calçada, R., and Cardoso, A. S.: Vibrations induced by railway traffic: influence of the mechanical properties of the train on the dynamic excitation mechanism, in: 8th European Conference on Structural Dynamics: Eurodyn 2011, edited by: De Roeck, G., Degrande, G., Lombaert, G., Müller, G., European Association for Structural Dynamics, Leuven (Belgium), 804811,2011

Costa, P., Calçada, R., and Cardoso, A. S.: Influence of train dynamic modelling strategy on the prediction of track-ground vi- brations induced by railway traffic, Proc. IMechE, Part F: J. Rail and Rapid Transit, 226, 434-450, 2012.

Deutsches Institut für Normung: DIN 4150-2: Structural vibrations - Part 2: Human exposure to vibration in buildings, 1999.

Do Rêgo Silva, J. J.: Acoustic and Elastic Wave Scattering using Boundary Elements, vol. 18, Computational Mechanics Publications, Southampton (UK), 1994.

François, S., Schevenels, M., Galvín, P., Degrande, G., and Lombaert, G.: Applications of a 2.5D coupled FE-BE methodology for the dynamic interaction between longitudinally invariant structures and the soil, in: 8th National Congress on Theoretical and Applied Mechanics, National Committee for Theoretical and Applied Mechanics, Brussels (Belgium), 2009.

Galvín, P. and Domínguez, J.: Experimental and numerical analyses of vibrations induced by high-speed trains on the CórdobaMálaga line, Soil Dyn. Earthq. Eng., 29, 641-651, 2009.

Garcia de Jalon, J. and Bayo, E.: Kinematic and Dynamic Simulation of Multibody Systems: the Real-time challenge, SpringerVerlag, New York, 1993.

Garg, V. and Dukkipati, R.: Dynamics of Railway Vehicle Systems, Academic Press Canada, Don Mills, Ontario, 1984.

Géradin, M. and Cardona, A.: Flexible Multibody Dynamics. A Finite Element Approach, John Wiley \& Sons, Chichester, England, 2000.

Hiller, M.: Dynamics of multibody system with minimal coordinates, in: Computer-Aided Analysis of Rigid and Flexible Mechanical Systems - Proceedings of the NATO Advanced Study Institute, edited by: Pereira, M. F. O. and Ambrosio, J. C., Tróia (Portugal), 119-163, 1993.

Ju, S.-H.: Finite element investigation of traffic induced vibrations, J. Sound Vib., 321, 837-853, 2009.

Kaynia, A. M., Madshus, C., and Zackrisson, P.: Ground vibration from high-speed trains: prediction and countermeasure, J. Geotech. Geoenviron., 126, 531-537, 2000.

Knothe, K. and Grassie, S. L.: Modelling of railway track and vehicle/track interaction at high frequencies, Vehicle Syst. Dyn., 22, 209-262, 1993.

Kouroussis, G., Verlinden, O., and Conti, C.: Ground propagation of vibrations from railway vehicles using a finite/infinite-element model of the soil, Proc. IMechE, Part F: J. Rail and Rapid Transit, 223, 405-413, 2009.

Kouroussis, G., Verlinden, O., and Conti, C.: On the interest of integrating vehicle dynamics for the ground propagation of vibrations: the case of urban railway traffic, Vehicle Syst. Dyn., 48, 1553-1571, 2010.

Kouroussis, G., Gazetas, G., Anastasopoulos, I., Conti, C., and Verlinden, O.: Lumped mass model of vertical dynamic coupling of a railway track on elastic homogeneous or layered halfspace, in: 8th European Conference on Structural Dynamics: Eurodyn 2011, edited by: De Roeck, G., Degrande, G., Lombaert, G., and Müller, G., European Association for Structural Dynamics, Leuven (Belgium), 676-683, 2011a.

Kouroussis, G., Gazetas, G., Anastasopoulos, I., Conti, C., and Verlinden, O.: Discrete modelling of vertical track-soil coupling for vehicle-track dynamics, Soil Dyn. Earthq. Eng., 31, 1711-1723, $2011 b$.

Kouroussis, G., Rustin, C., Bombled, Q., and Verlinden, O.: EasyDyn: multibody open-source framework for advanced research purposes, in: Multibody Dynamics 2011, edited by: J. C. Samin 
and Fisette, P., ECCOMAS Thematic Conference, Brussels (Belgium), 2011c.

Kouroussis, G., Van Parys, L., Conti, C., and Verlinden, O.: Prediction of environmental vibrations induced by railway traffic using a three-dimensional dynamic finite element analysis, in: Proceedings of the Thirteenth International Conference on Civil, Structural and Environmental Engineering Computing, edited by: Topping, B. H. V. and Tsompanakis, Y., Civil-Comp Press, Chania (Greece), 2011d.

Kouroussis, G., Verlinden, O., and Conti, C.: Free field vibrations caused by high-speed lines: measurement and time domain simulation, Soil Dynam. Earthq. Eng., 31, 692-707, 2011 e.

Kouroussis, G., Verlinden, O., and Conti, C.: A two-step time simulation of ground vibrations induced by the railway traffic, J. Mech. Eng. Sci., 226, 454-472, 2012a.

Kouroussis, G., Verlinden, O., and Conti, C.: Efficiency of resilient wheels on the alleviation of railway ground vibrations, Proc. IMechE, Part F: J. Rail and Rapid Transit, 226, 381-396, 2012 b.

Kouroussis, G., Verlinden, O., and Conti, C.: Influence of some vehicle and track parameters on the environmental vibrations induced by railway traffic, Vehicle Syst. Dyn., 50, 619-639, 2012c.

Kouroussis, G., Conti, C., and Verlinden, O.: Investigating the influence of soil properties on railway traffic vibration using a numerical model, Vehicle Syst. Dyn., 51, 421-442, 2013.

Lefeuve-Mesgouez, G., Peplow, A. T., and Houédec, D. L.: Surface vibration due to a sequence of high speed moving harmonic rectangular loads, Soil Dyn. Earthq. Eng., 22, 459-473, 2002.
Parisse, B. and Graeve, R. D.: Giac/Xcas (version 0.8.6), http: //www-fourier.ujf-grenoble.fr/ parisse/giac_fr.html, last access: September 2010.

SciFace Software GmbH \& Co: MuPAD, http://www.mupad.de, last access: July 2012.

Shabana, A. A.: Dynamics of Multibody Systems, Cambridge University Press, New York, USA, 2005.

Takemiya, H. and Bian, X.: Substructure simulation of inhomogeneous track and layered ground dynamic interaction under train passage, J. Eng. Mech., 131, 699-711, 2005.

Verlinden, O., Ben Fekih, L., and Kouroussis, G.: Symbolic generation of the kinematics of multibody systems in EasyDyn: from MuPAD to Xcas/Giac, Theoretical and Applied Mechanics Letters, 3, 013012, doi:10.1063/2.13013012, 2013.

Wang, J. and Zeng, X.: Numerical simulations of vibration attenuation of high-speed train foundations with varied trackbed underlayment materials, J. Vib. Control, 10, 1123-1136, 2004.

Wang, J., Zeng, X., and Gasparini, D. A.: Dynamic response of high-speed rail foundations using linear hysteretic damping and frequency domain substructuring, Soil Dyn. Earthq. Eng., 28, 258-276, 2008.

Zhai, W. and Sun, X.: A detailed model for investigating vertical interaction between railway vehicle and track, Vehicle Syst. Dyn., 23 (supplement), 603-615, 1994. 